\title{
Hexokinase II integrates energy metabolism and cellular protection: Akting on mitochondria and TORCing to autophagy
}

\author{
This article has been corrected since Advance Online Publication and corrigendum is also printed in this issue
}

\author{
DJ Roberts ${ }^{1}$ and S Miyamoto*,1
}

Accumulating evidence reveals that metabolic and cell survival pathways are closely related, sharing common signaling molecules. Hexokinase catalyzes the phosphorylation of glucose, the rate-limiting first step of glycolysis. Hexokinase II (HK-II) is a predominant isoform in insulin-sensitive tissues such as heart, skeletal muscle, and adipose tissues. It is also upregulated in many types of tumors associated with enhanced aerobic glycolysis in tumor cells, the Warburg effect. In addition to the fundamental role in glycolysis, HK-II is increasingly recognized as a component of a survival signaling nexus. This review summarizes recent advances in understanding the protective role of HK-II, controlling cellular growth, preventing mitochondrial death pathway and enhancing autophagy, with a particular focus on the interaction between HK-II and Akt/mTOR pathway to integrate metabolic status with the control of cell survival.

Cell Death and Differentiation (2015) 22, 248-257; doi:10.1038/cdd.2014.173; published online 17 October 2014

Facts

- Hexokinase II phosphorylates glucose to regulate glucose metabolism but also functions as a protective signaling molecule.

- Hexokinase II is the predominant isoform in insulinsensitive tissues and upregulated in tumors.

- Hexokinase II expression is regulated by the Akt/mTOR pathway.

- Hexokinase II is phosphorylated by Akt leading to increased mitochondrial binding and mitochondrial protection.

- Hexokinase II binds and inhibits TORC1 to facilitate autophagy in response to glucose deprivation.

\section{Open Questions}

- What is the molecular mechanism by which Akt-mediated phosphorylation of HK-II increases mitochondrial association?

- How is HK-II/TORC1 binding regulated by the level of glucose-6-phosphate?

- How significant is the physiological/pathophysiological regulation of autophagy mediated by HK-II in vivo?
- It remains unclear how mitochondrial HK-II prevents opening of the mitochondrial permeability transition pore.

\section{Hexokinase II in Metabolism}

Hexokinases (HKs) catalyze the first committed step of glucose metabolism. Glucose transported through glucose transporters (GLUTs) on the plasma membrane is phosphorylated by $\mathrm{HKs}$ to produce glucose-6-phosphate (G-6P). The activity of $\mathrm{HKs}$ is inhibited by G-6P providing a feedback inhibition mechanism. ${ }^{1-5}$ G-6P serves as a precursor for glycolysis (ATP) as well as the pentose phosphate pathway (NADPH and ribulose-5-P), glycogenesis (glycogen) and hexosamine biosynthetic pathway (UDP-GlcNAc) $)^{2-5}$ (Figure 1a). HK therefore plays important roles in the regulation of anabolic and catabolic processes.

There are four isoforms of HK: I, II, III and IV (aka glucokinase) in mammalian tissues (Figure 1b). Glucokinase has a molecular mass of $\sim 50 \mathrm{kDa}$ while $\mathrm{HK}-\mathrm{I}$, II and III have a molecular weight of $\sim 100 \mathrm{kDa}$ resulting from the evolutionary duplication and fusion of a single domain HK molecule. ${ }^{2,4-6}$ The catalytic activity of both domains is preserved in HK-II

\footnotetext{
${ }^{1}$ Department of Pharmacology, University of California, San Diego, 9500 Gilman Drive, La Jolla, CA, USA

*Corresponding author: S Miyamoto, Department of Pharmacology, University of California, San Diego, 9500 Gilman Drive, La Jolla, CA 92093-0636, USA. Tel: +1 858534 1368; Fax: +1 858534 4337; E-mail: smiyamoto@ucsd.edu

Abbreviations: 2-DG, 2-deoxy-D-glucose; Akt, murine thymoma viral (v-akt) oncogene homolog; AMPK, AMP-activated protein kinase; ANT, adenine nucleotide translocase; Bak, Bcl-2-antagonist/killer; Bax, Bcl-2-associated x protein; Bcl-2, B-cell leukemia/lymphoma-2; Bid, BH3-interacting domain death agonist; CyPD, Cyclophilin D; DMPK, myotonic dystrophy protein kinase; Fru-2,6-BP, fructose-2,6-bisphosphatase; G-6P, glucose-6-phosphate; GLUT, glucose transporter; GPI, glucose6-phosphate isomerase; GSK-3 $\beta$, glycogen synthase kinase-3 $\beta$; $\mathrm{H}_{2} \mathrm{O}_{2}$, hydrogen peroxide; HK, Hexokinase; HIF-1, hypoxia-inducible factor 1 ; KO mice, knockout mice; miRNA, microRNA; mitoHK, mitochondrially associated hexokinase; MOM, mitochondrial outer membrane; mRNA, messenger RNA; mTOR, mammalian (mechanistic) target of rapamycin; mTORC1 and mTORC2, mTOR complex 1 and 2, respectively; mPTP, mitochondrial permeability transition pore; p53, tumor protein p53; PI3K, phosphatidylinositol 3-kinase; PHLPP, PH domain leucine-rich repeat protein phosphatase; ROS, reactive oxygen species; Thr, threonine; TIGAR, Tp53-induced glycolysis and apoptosis regulator; TG mice, transgenic mice; TOS motif, mTOR signaling motif; UCP, Uncoupling protein; UDP-GIcNAc, Uridine diphosphate N-acetylglucosamine; ULK1, unc-51-like autophagy-activating kinase 1; VDAC1, voltage-dependent anion channel 1

Received 03.7.14; revised 11.9.14; accepted 15.9.14; Edited by JM Hardwick; published online 17.10.14
} 
a

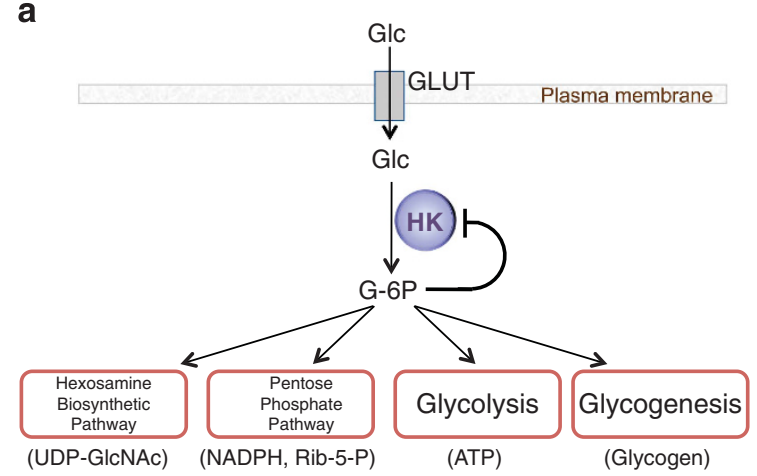

b

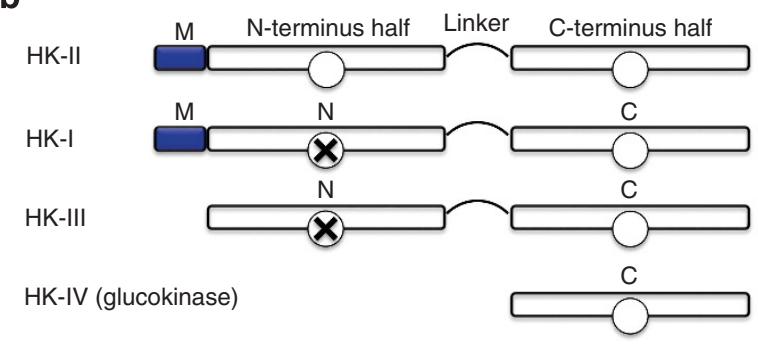

C
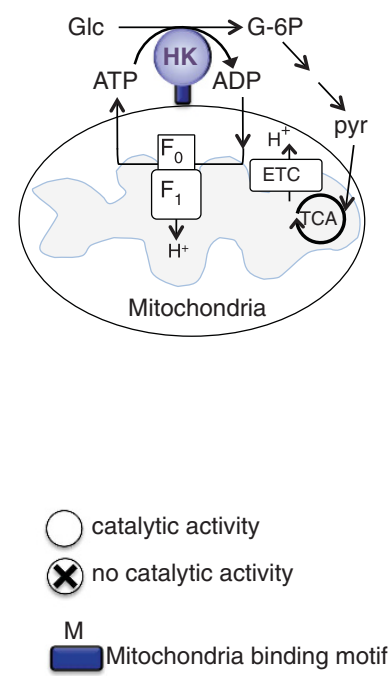

Figure 1 Hexokinase overview. (a) Metabolic roles of hexokinase. (b) Hexokinase subtypes. (c) Tight coupling of mitoHK to ATP generated by mitochondria provides energetic advantage

while activity is restricted to the carboxyl terminal domain of HK-I and HK-III. HK-I, II and III have higher affinity for glucose compared to $\mathrm{HK}-\mathrm{IV}^{2,4,5,7} \mathrm{HK}-\mathrm{I}$ is the main isoform in the brain, but also ubiquitously expressed. ${ }^{4,5} \mathrm{HK}-\mathrm{Il}$ is the predominant isoform in insulin-sensitive tissues such as adipose, skeletal and cardiac muscle. ${ }^{8} \mathrm{HK}-\mathrm{III}$ is also ubiquitously expressed but not predominant in any tissue while the expression of HK-IV, glucokinase, is restricted primarily to the liver and pancreas. $^{2-5}$

Studies in the 1960s identified that significant quantities of HK-I and HK-II bind to the outer mitochondrial membrane $e^{9,10}$ via a mitochondrial binding motif at the $\mathrm{N}$-terminal. ${ }^{11,12} \mathrm{HK}-\mathrm{II}$ binds to voltage-dependent anion channel 1 (VDAC1), the outer mitochondrial membrane protein, which interacts with the adenine nucleotide translocase (ANT), forming a contact site between the outer and inner membranes. ${ }^{3,4,13-16}$ The mitochondrially bound $\mathrm{HKs}$ provide facilitation of coupling between glycolysis and oxidative phosphorylation through privileged/preferential access of HKs to ATP generated by mitochondria. The ADP generated by mitochondrial HK catalytic activity is shuttled back into mitochondria for rephosphorylation conferring metabolic advantage ${ }^{4,17,18}$ (Figure 1c). The binding to mitochondria also undergoes feedback inhibition by G-6P. ${ }^{9,19-22}$

In the last decade, many seminal studies have emphasized the importance of metabolic re-programming in cancer biology. HK-II upregulation has been suggested to be a major contributor to the elevated glycolysis, even in the presence of oxygen, in cancer as first reported by Dr. Otto Warburg ${ }^{23}$ in 1930 (Warburg effect). During tumor development in tissues normally expressing HK-IV, gene expression of HK-II is induced whereas HK-IV is silenced. ${ }^{24-28}$ This switch from a lower to a higher affinity HK subtype can provide a means to meet the high energy demand in tumors. Indeed, HK-II expression levels are closely associated with tumor grade and mortality in hepatocellular carcinoma. ${ }^{29}$ Although in normal brain and low-grade gliomas HK-I is the predominant isoform, HK-II is highly upregulated in human glioblastoma multiforme ${ }^{30}$ and poor prognosis is associated with upregulation of HK-II in human brain metastases of breast cancer. ${ }^{31}$ Thus HK-II upregulation is considered a consequence of metabolic re-programming in cancer.

Akt is a serine/threonine kinase often upregulated in tumor cells. Akt is activated by a wide range of receptor stimuli to regulate diverse functions including glucose metabolism, cellular growth and survival through phosphorylation of many different target molecules at different cellular compartments. ${ }^{32-36}$ One of the most established downstream effectors of Akt is the mammalian (mechanistic) target of rapamycin (mTOR), a serine/threonine kinase. mTOR forms two distinct functional complexes termed mTOR complex 1 and 2 (mTORC1 and mTORC2). Raptor and rictor are the defining component of $\mathrm{mTORC} 1$ and mTORC2, respectively. ${ }^{37-40}$ In addition to its fundamental role in metabolism, it is becoming increasingly recognized that HK-II functions as a protective molecule, exerting antioxidant effects, direct protection of mitochondria against stress, and facilitation of autophagy under starvation. The direct molecular-molecular or functional interactions between HK-II and the Akt/mTOR pathways that have been identified act to integrate metabolism and cell survival, providing adaptive mechanisms in response to changes in the cellular environment. Below we summarize recent advances in our understanding of the transcriptional- and post-transcriptional interaction of these protective signaling molecules. 


\section{Regulation of HK-II Expression by Akt/mTORC1 Pathway}

HK-II is a constitutively active kinase and the changes in the expression level of HK-II directly impact cellular glucose metabolism. HK-Il expression undergoes dynamic changes in various diseases. As mentioned earlier, the expression of HKII is increased in many tumors while it is remarkably decreased in type-I diabetes (insulin-dependent diabetes). ${ }^{41-45}$ Concomitantly, Akt activity is upregulated in tumors and insulin treatment recovers HK-II levels in diabetes. ${ }^{41-44}$ The correlation between Akt activity and HK-II expression suggest the transcriptional regulation of HK-II by Akt, which has been supported by many studies. Insulin treatment increases HK-II mRNA and protein in various cell types and the increase is blocked by inhibition of PI3K, an upstream kinase of Akt, as well as inhibition of mTORC1, suggesting Akt/mTORC1 contribution $^{44,46-51}$ (Figure 2). Hyperactivity of mTORC1 is sufficient to increase HK-II expression ${ }^{52}$ and a recent comprehensive and unbiased analysis also supports mTORC1-mediated HK-II upregulation and further demonstrated that $\mathrm{mTORC} 1$ signaling activates the genes encoding nearly every step of glycolysis. ${ }^{53}$

Hypoxia-inducible factor 1 (HIF-1) is a transcription factor. The $a$-subunit of HIF-1 (HIF-1a) is stabilized under hypoxic conditions, leading to the activation of a transcriptional program to adapt to the lack of oxygen. The HK-II promoter has a consensus motif for HIF-1 $1^{54,55}$ and HK-II expression is enhanced by hypoxia, ${ }^{54-57}$ providing cellular protection ${ }^{52,56}$ as well as a mechanism for elevated glycolysis in tumors. ${ }^{58-60,61}$ $\mathrm{HIF}-1 \mathrm{a}$ expression is also under the control of the PI3K/Akt/ mTORC1 pathway, ${ }^{53,62-65}$ linking Akt/mTOR activation and HK-II upregulation. mTORC1 increases HIF-1a expression through regulation of transcription and translation of HIF- $1 a{ }^{53,59}$ a mechanism distinct from the control of HIF-1a protein stability. Indeed HIF-1a expression is demonstrated to be responsible for mTORC1-induced HK-II upregulation. ${ }^{52}$

microRNAs (miRNAs) are small, non-coding RNAs and post-transcriptional inhibitory regulators of gene expression. miR-143, a tumor suppressor miRNA, which is downregulated

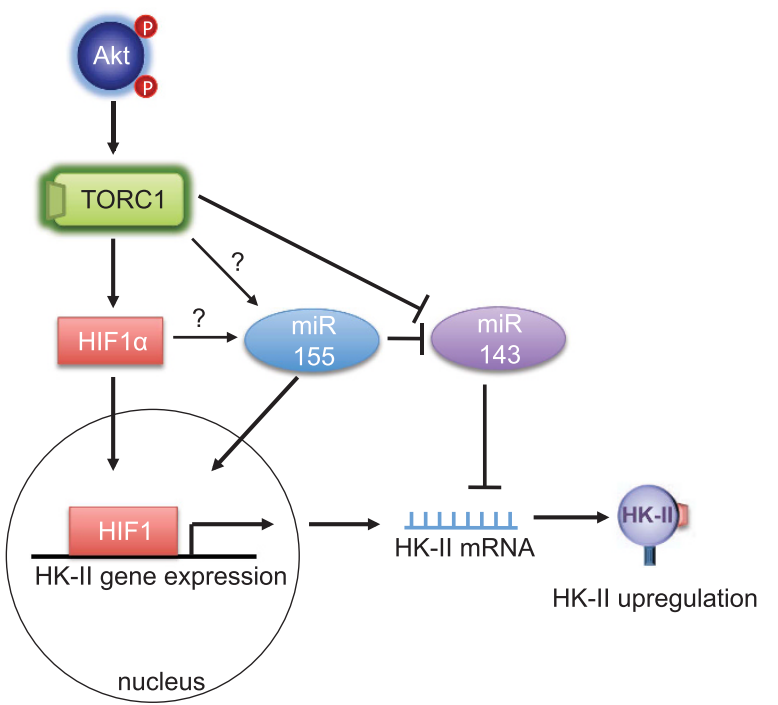

Figure 2 Regulation of HK-II expression mediated by Akt/mTORC1 pathway in many tumors, ${ }^{66}$ targets HK-II mRNA. ${ }^{67-72}$ miR-143 is also expressed in the heart where forced expression decreases the expression of HK-II. ${ }^{73}$ Conversely, oncogenic miR-155 upregulates HK-Il gene expression in tumor cells by downregulation of miR-143 as well as upregulating HK-II transcription. ${ }^{74}$ In the context of regulation of miR-143 expression, it is worth pointing out that inhibition of $\mathrm{mTOR}$ is reported to increase the level of miR-143, and thus decrease HK-II expression, suggesting that mTORC1 suppresses miR-143 expression to increase HK-II. ${ }^{67,72}$ The regulation of miR-143 expression could therefore be one of the mechanisms by which the Akt/mTORC1 pathway upregulates HK-II expression. The mechanism by which mTORC1 could inhibit miR-143 expression, that is mTORC1- and/or HIF-1-mediated upregulation of miR-155, has not been elucidated (Figure 2).

\section{Pro-survival Effect of HK-II}

Protective effect of ectopic expression of HK-II have been established in many different cell types. ${ }^{75-82}$ Conversely, decreased HK-II levels sensitize cells to apoptotic or necrotic stimuli. Overexpression of HK-II confers cellular protection against $\mathrm{H}_{2} \mathrm{O}_{2}$ in cardiomyocytes ${ }^{79,80,82}$ and also prevents maladaptive hypertrophy in vivo heart. ${ }^{82}$ Heterozygotic HK-II knockout hearts are more susceptible to ischemia/reperfusion injury as well as pressure overload. ${ }^{83,84}$ Overexpression of $\mathrm{HK}-\mathrm{II}$ is proliferative and anti-apoptotic while reduction of HK-II expression in glioblastoma multiforme is anti-tumorgenic in vivo. ${ }^{30}$ An earlier study revealed that increased glucose phosphorylation by co-expression of GLUT1 and HK-I in the hematopoietic cell line increases cytosolic NADPH levels and elicits an anti-apoptotic effect. ${ }^{85}$ Thus the protective effect of HK-II could be due to its cytosolic activity to increase NADPH levels through the pentose phosphate pathway producing antioxidant effects. ${ }^{80}$ This hypothesis is supported by a recent paper using cardiac-specific HK-II transgenic (TG) mice. ${ }^{82}$ Cardiac hypertrophy induced by isoproterenol infusion is attenuated in the TG mice and this is accompanied by reduced reactive oxygen species (ROS) levels in cardiomyocytes overexpressing HK-II. The anti-hypertrophic and antioxidant effects of overexpression of HK-II are reversed by inhibition of glucose-6-phosphate dehydrogenase, an enzyme responsible for reducing NADP to NADPH, suggesting that HK-II attenuates cardiac hypertrophy by decreasing ROS via increased pentose phosphate pathway flux. ${ }^{82}$

Further, mitochondrially associated HKs (mitoHKs) can exert protective effects on mitochondria to prevent mitochondrial death pathways. A major mitochondrial death pathway is elicited by apoptotic Bcl-2 family proteins such as Bax and Bak and/or the mitochondrial permeability transition pore (mPTP), a mega channel formed at the mitochondrial inner membrane. ${ }^{86-90}$ Activated Bax/Bak forms a pore at the mitochondrial outer membrane (MOM) resulting in a release of apoptotic factors from the intra-membrane space. ${ }^{86,91}$ MitoHK-II antagonizes apoptotic Bcl-2 family proteins and thereby protects cells against apoptotic stimuli. ${ }^{15,78,92-95}$ MitoHK-II competitively inhibits Bax binding to mitochondria ${ }^{15,78}$ and also antagonizes truncated Bid (tBid) induced Bax/Bak-mediated apoptosis. ${ }^{94}$ MitoHK-II also provides protection against the mPTP. Mitochondrial $\mathrm{Ca}^{2+}$ 
overload and/or ROS induce opening of the $\mathrm{MPTP}$, resulting in a large amplitude permeability of the inner membrane, consequent rupture of the outer mitochondrial membrane and resultant necrotic (and somewhat apoptotic) cell death. ${ }^{86-90}$ Majewski et al. ${ }^{93}$ demonstrated that mitoHK-II provides cellular protection against $\mathrm{Ca}^{2+}$ overload even in $\mathrm{Bax}$ and Bak double-knockout cells. We and others have also reported that an increase in mitoHK-II has an inhibitory effect on $\mathrm{Ca}^{2+}$ - and ROS-induced MPTP opening and that a large dissociation of mitoHK-II sensitizes MPTP opening and cell death. ${ }^{77,80,82,83,96-98}$

A series of studies have demonstrated that mitoHK-II has an ability to decrease ROS generation at mitochondria to prevent opening of the mPTP. ${ }^{77,80,82,84,99}$ As mentioned earlier, mitoHK ensures tight coupling of glucose phosphorylation and mitochondrial ATP generation. This increases electron flow in the mitochondria and thus decreases mitochondrial membrane potential, which can reduce mitochondrial ROS emission. ${ }^{77,99}$ It has also been demonstrated that mitoHK-II has a direct inhibitory effect on the MPTP. The mechanism for the protection is not known, largely because the molecular composition of mPTP is not fully identified. However, cyclophilin D (CyPD) is established to be a critical positive regulator since its gene deletion results in remarkable reduction in the sensitivity of opening of the MPTP and confers strong protection. ${ }^{100,101}$ Interestingly, CyPD activity stabilizes mitoHK-II binding and forced dissociation of mitoHK-II leads to disruption of CyPD binding to ANT, suggesting a functional link between a stimulatory (CyPD) and an inhibitory (HK-II) molecule of the mPTP. ${ }^{96,102-105}$ It seems likely that the interaction between HK-II and CyPD is mediated by the previously mentioned VDAC/ANT interaction. ${ }^{106,107}$ However, genetic evidence revealed that neither VDAC nor ANT is the main pore-forming component ${ }^{108-111}$ and thus it is still not clear whether the indirect interaction of HK-II with CyPD plays a direct role in regulation of the MPTP. A recent seminal study proposed that the dimer of $F_{0} F_{1}$ ATP synthase could be the pore-forming core components of the MPTP and the sensitivity of the pore formation is positively regulated by CyPD binding to the synthase. ${ }^{112}$ It will be of considerable interest to determine whether mitoHK-II binding has a regulatory role on CyPD binding to $F_{0} F_{1}$ ATP synthase to inhibit pore formation.

It has been disputed whether Bax/Bak regulates MPTP opening. Recent genetic studies revealed that deletion of Bax/ Bak inhibits MPTP opening and necrotic cell death induced by $\mathrm{Ca}^{2+}$ overload or ROS, suggesting the ability of Bax/Bak to facilitate MPTP-induced cell death. ${ }^{113,114}$ Thus the aforementioned mitoHK-II-mediated inhibition of Bax binding to mitochondria could contribute to the anti-mPTP effect of mitoHK-II. Further studies will be required to delineate the interaction of these molecules to determine the mechanism by which HK-II prevents MPTP opening.

Although HK-I has similar pro-survival properties to HK-II, HK-II is preferentially upregulated by cancers. What benefits does HK-II therefore provide over HK-I? (1) The expression of HK-II is regulated by pro-survival/stress response pathways, which are necessarily activated for cancer survival and growth. (2) The catalytic activity of both $\mathrm{N}$ - and $\mathrm{C}$-terminus is preserved in HK-II, but not in HK-I nor in -III, and these two domains in $\mathrm{HK}-\mathrm{Il}$ are different in their affinities to
G-6P-dependent catalytic inhibition. The C-terminal half has $\sim 30$-fold higher $K i$ value than the $\mathrm{N}$-terminal half (which is similar to HK-I), and HK-II could retain its catalytic activity under conditions in which $\mathrm{HK}-\mathrm{I}$ catalytic activity is inhibited. ${ }^{1,5,115}$ (3) Adaptability. As discussed below, Akt phosphorylates HK-II leading to increase in mitoHK-II. Although HK-I binds to mitochondria and provides protection, it lacks an Akt phosphorylation site and thus is not regulated by Akt. ${ }^{20}$ Akt-mediated regulation of mitoHK-II may render HK-II more regulatory and versatile to allow tumor cells adapt to changes in the metabolic condition. Glycogen synthesis and the pentose phosphate pathway are upregulated in tumor cells subjected to hypoxia. ${ }^{116}$ Thus, in response to ischemia, in which Akt activity and mitoHK-II are decreased (resulting in increased cytosolic HK-II), HK-II would stimulate these cytosolic events to preserve cellular homeostasis. (4) As discussed later, non-mitochondrial HK-II facilitates autophagy induced by glucose withdrawal, ${ }^{117}$ suggesting regulation of energy conservation by HK-II.

\section{Akt and Mitochondrial HK-II in Protection}

Akt stimulates glycolysis and also elicits strong cell survival in many organs. ${ }^{32-36}$ Earlier studies found that expression of active Akt increases mitochondrial HK activity and the antiapoptotic effect of Akt required mitoHK. ${ }^{118}$ The aforementioned inhibitory effect of mitoHK-II on tBid is also downstream of Akt, contributing to Akt-mediated protection. ${ }^{94}$ Further, mitoHK-Il increased by Akt overexpression confers protection in Bax/Bak null cells, suggesting inhibition of $\mathrm{MPTP}^{93}$ and our previous work in cardiomyocytes also showed that Akt activation increases the level of mitoHK-II leading to inhibition of mPTP opening and cell death. ${ }^{79,97}$ In the heart, in which HKII is the predominant isoform, mitoHK-II activity is known to be increased by many cardioprotective interventions such as insulin, morphine and ischemic preconditioning. ${ }^{119-121}$

Given that Akt leads to increased mitoHK-II, we explored the possibility that Akt directly phosphorylates HK-II. Our previous study revealed that HK-II, but not HK-I or HK-III, has an Akt consensus sequence at position Thr473 (RARQKT*), which is preserved in mouse, rat and human. ${ }^{97}$ We found that Akt, activated by receptor agonists, translocates to mitochondria and phosphorylates HK-II at Thr473, a critical step in Akt-mediated mitoHK-II increase and protection in cardiomyocytes $^{79,97}$ (Figure 3). Other studies also support that Akt increases mitoHK-II in cardiac and non-cardiac cells. ${ }^{20,122-126}$

PHLPP (PH domain leucine-rich repeat protein phosphatase) is a protein phosphatase $2 \mathrm{C}$ family member which has been discovered to dephosphorylate and inhibit Akt. ${ }^{126-130}$ Expression of PHLPP is repressed in cancer cells resulting in elevated Akt activation. ${ }^{128,130}$ Interestingly, our study using PHLPP1 knockout (KO) mice suggest that PHLPP1, in addition to cytosol, localizes at mitochondria and negatively regulates mitochondrial Akt activity, decreasing mitoHK-II. ${ }^{124}$ These findings have been confirmed in non-cardiac cells. ${ }^{126}$ Thus the levels of mitoHK-II are regulated through a dynamic balance between kinase and phosphatase.

We demonstrated that phosphorylation of HK-II at Thr473 acted to decrease the sensitivity of HK-II to G-6P induced 


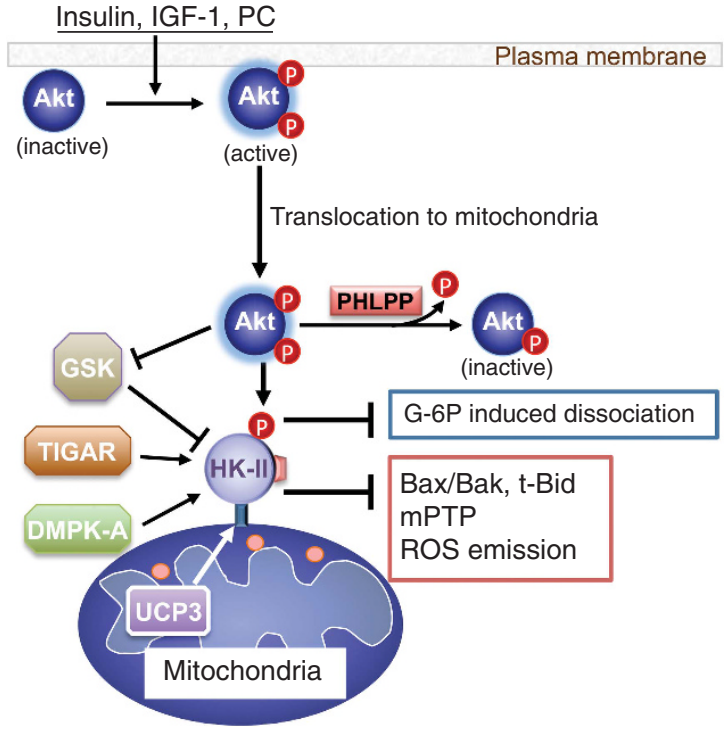

Figure 3 MitoHK-II regulation and mitochondrial protection

mitochondrial dissociation thereby increasing the net binding. ${ }^{79}$ The kinetics of G-6P product inhibition of HK-II catalytic activity was not affected by phosphorylation, indicating that this modification does not reduce the affinity of G-6P binding to the kinase. ${ }^{79}$ Although it is unclear how phosphorylation decreases the sensitivity of the kinase to G-6Pmediated dissociation, Thr473 in HK-II is located at the 'linker' region connecting the two kinase halves, thus phosphorylation could induce conformational change of the kinase to increase binding to its mitochondrial protein partner. HK-I has been suggested to form a tetramer preferentially at mitochondria, which becomes more resistant to product inhibition relative to the cytosolic monomeric kinase..$^{3,4,131,132}$ Although the possibility of tetramerization of HK-II has not been studied, it is notable that the region in HK-I analogous to the HK-II Thr473 region contains negative charges compared to the more positive HK-II. By adding back a negative charge to this region, Akt-mediated phosphorylation may therefore facilitate HK-II tetramer formation at mitochondria, suppressing G-6P-dependent mitoHK-II release.

\section{Other Modulation of mitoHK-II}

Emerging evidence has revealed other mechanisms to regulate the level of mitoHK-II (Figure 3). (1) In addition to direct modification of HK-II, Akt has been demonstrated to increase mitoHK-II through inhibition of glycogen synthase kinase- $3 \beta$ (GSK-3 $\beta$ ). GSK- $3 \beta$ is a constitutively active kinase and phosphorylates VDAC, inhibiting HK-II binding. ${ }^{87,92,133,134}$ Akt phosphorylates and inhibits GSK-3 $\beta$ resulting in decreased suppression of mitoHK-II. (2) A recent study revealed another kinase-dependent regulation of mitoHK-II. Mutation in the myotonic dystrophy protein kinase (DMPK) gene, coding a serine/threonine kinase, causes myotonic dystrophy type 1. DMPK-A is a subtype which preferentially associates with mitochondria. DMPK-A forms a molecular complex with Src and HK-II at the MOM in skeletal muscle cells subjected to oxidative stress and stabilizes mitoHK-II binding to confer antioxidant protection. ${ }^{135}$ (3) Uncoupling proteins (UCPs) are mitochondrial anion carrier proteins that mitigate mitochondrial ROS emission, probably by regulating the mitochondrial membrane potential. ${ }^{136} \mathrm{~A}$ recent study using UCP3 KO mice showed that UCP3 enhanced mitoHK-II binding in skeletal muscle, participating in a UCP3-mediated decrease in ROS emission. ${ }^{99}$ (4) Another intriguing regulatory mechanism of mitoHK-II was obtained from studies of p53, a key tumor suppressor. In addition to the established role of p53 in cell cycle arrest and apoptosis, recent evidence has demonstrated that $\mathrm{p} 53$ reduces glycolytic flux and increases oxidative phosphorylation, halting the Warburg effect. ${ }^{137-143}$ TIGAR (Tp53-induced glycolysis and apoptosis regulator) was identified to function as a fructose-2,6-bisphosphatase (Fru$2,6-B P)$, antagonizing the third step of glycolysis and thereby redirecting metabolite flux to the pentose phosphate pathway. ${ }^{138-140}$ Interestingly, basal or low levels of p53 expression have been suggested to provide antioxidant effects and thus elicit cellular protection rather than cell death. ${ }^{138-140} \mathrm{~A}$ recent study has discovered an unexpected mechanism of TIGAR to decrease ROS generation at mitochondria. ${ }^{144}$ TIGAR, upon hypoxia, translocates to mitochondria and interacts with mitoHK-II, stabilizing mitoHK-II and thereby decreasing mitochondrial ROS generation and providing cellular protection. This effect was independent of its Fru-2,6-BP activity. Thus TIGAR inhibits oxidative stress through two distinct mechanisms in cytosol and at mitochondria. Taken together this new evidence reveals that mitoHK-II is a convergence of various protective signals to adapt to stress conditions.

\section{HK-II-mediated Regulation of mTORC1 and Autophagy}

In the face of limited energy availability, cells initiate a process of catabolic self-digestion termed macroautophagy (hereafter referred to as autophagy) to ensure cellular energy homeostasis and survival. Autophagy means self-eating in Greek and can function as an intracellular recycling system by which intracellular contents and damaged organelles undergo degradation through their sequestration within autophagosomes and lysosomal degradation to supply energy substrates. ${ }^{145-153}$

mTORC1 is a critical negative regulator of autophagy. ${ }^{40,59,154}$ mTORC1 phosphorylates and inhibits the autophagy-activating kinase ULK1. ${ }^{155,156}$ Upon nutrient deprivation, the activity of $\mathrm{mTORC} 1$ is suppressed and AMPK is activated. Consequently, ULK1 is activated and initiates membrane nucleation, which is followed by sequestration and degradation. ${ }^{155-160}$ Although it has been widely accepted that autophagy is induced in response to metabolic suppression, the molecular links between metabolic and autophagic pathways have not been fully elucidated. Recently, we made the surprising discovery that HK-II facilitates autophagy in response to glucose deprivation to protect cells ${ }^{117}$ (Figure 4).

The initial observation for this unexpected role of HK-II was derived from experiments using 2-deoxy-D-glucose (2-DG). 2-DG is an analog of glucose, which is phosphorylated by HKs but not metabolized further, thus it is used as a HK inhibitor by many studies and in clinical trials for cancer therapy. ${ }^{161-163} \mathrm{We}$ observed that a low concentration of 2-DG (500 $\mu \mathrm{M}$ compared 


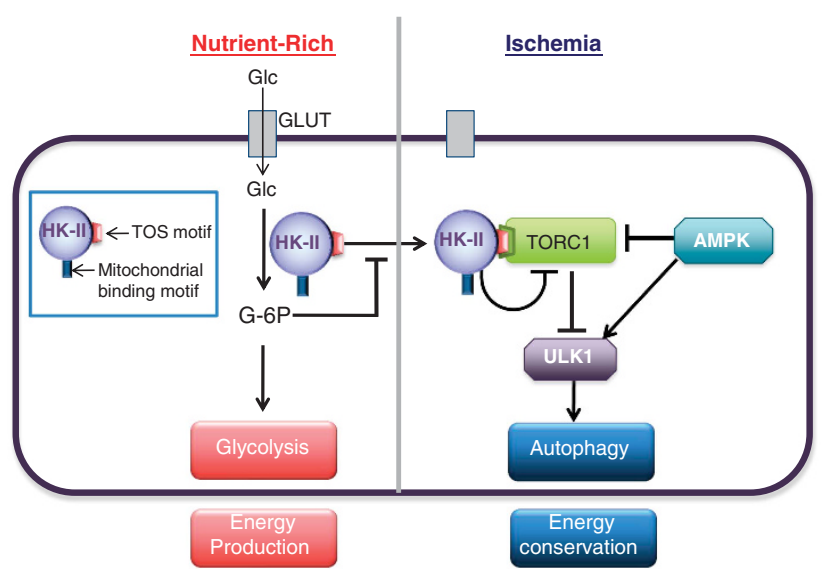

Figure 4 HK-II binds to and inhibits mTORC1 to facilitate autophagy in response to glucose deprivation

with 5-25 mM commonly used ${ }^{164-166}$ ) inhibited autophagy development in the absence of glucose in cardiomyocytes. This observation implied that HK-II acts to stimulate autophagy in the absence of its substrate. Autophagy induced by glucose deprivation is attenuated by HK-II knockdown but potentiated by its overexpression. By comparison, HK-I knockdown or overexpression does not affect the development of autophagy. These observations suggest that HK-II can switch between energy production and energy conservation pathways dependent on the availability of glucose. Remarkably this autophagic effect of HK-II is independent of its mitochondrial binding as well as its kinase-activity, suggesting a previously unrecognized, non-mitochondrial scaffold function to confer cellular protection. A series of experiments demonstrated that HK-II binds to mTORC1 in the absence of glucose, decreasing mTORC1 activity. ${ }^{117}$ This interaction was mediated by an mTOR signaling motif (TOS motif), identified at positions 199-203 (FDIDI) in HK-II but absent in HK-I. The sequence is found in various species, including mouse, rat, horse, boar and human HK-II, suggesting that the TOS motif in $\mathrm{HK}-\mathrm{Il}$ is well conserved. The TOS motif is critical for mTORC1 substrate binding to raptor and subsequent phosphorylation by mTOR. ${ }^{167,168}$ Notably, expression of HK-II with a mutated TOS motif fails to bind to or inhibit mTORC1 and does not increase autophagy induced by glucose deprivation. Thus, in the absence of glucose, HK-II binds mTORC1 via its TOS motif, acting as a decoy substrate to facilitate autophagy. ${ }^{117} \mathrm{As}$ discussed earlier, mTORC1 activation stimulates HK-II expression under growth conditions conferring metabolic support while HK-II provides negative feedback to mTORC1 under starvation to stimulate autophagy. This dual regulation for HK-II and mTOR provides an adaptive mechanism to preserve cellular homeostasis dependent on metabolic status.

What regulates the switch between the glycolytic and autophagic roles of HK-II? We found that, in contrast to 2DG, the glucose analog 5-thio-glucose, which binds to HK-II but cannot be phosphorylated, does not inhibit autophagy induced by glucose deprivation. ${ }^{117}$ This suggests that phosphorylated glucose, but not glucose binding, is the key factor responsible for suppressing the autophagic effect of HK-II. To support this hypothesis, it was demonstrated that expression of a kinase-dead HK-II mutant (in the absence of endogenous HK-II) stimulated autophagy that was insensitive to inhibition by glucose, while expression of WT HK-II retained glucose dependent regulation. ${ }^{117}$ These observations lead us to conclude that accumulation of G-6P results in inhibition of the autophagic effect of HK-II in glucose-rich conditions.

It remains to be determined how G-6P inhibits the binding of HK-Il to mTORC1. We speculate that G-6P changes the intracellular localization of HK-II to regulate the association of HK-II with mTORC1. As mentioned above, mitochondria are not the location where the interaction occurs, thus it will be critical to identify the intracellular compartment for the interaction triggered by decreased level of G-6P. Recent studies have identified lysosomes as an activation site for TORC1. ${ }^{169-171}$ In response to a decrease in G-6P levels, HK-II may translocate to the lysosome to inhibit mTORC1. Although much additional study will be required to determine the precise mechanism by which G-6P inhibits the binding of HK-II to mTORC1, nonetheless, it provides a molecular basis for previous observations showing that $\mathrm{mTOR}$ activation requires glucose in cardiomyocytes ${ }^{172}$ and that an increase in the work load in the heart is associated with G-6P accumulation and mTOR activation. ${ }^{173}$ This suggests that HK-II acts as a glucose/G-6P sensor, allowing it to monitor and react to changes in status of glucose metabolism, to adjust the balance between glycolysis-/mTORC1-mediated growth and autophagy-mediated preservation of energy homeostasis. This signaling axis could shed light on the mechanism underlying some metabolic disorder diseases, since mTORC1 has been demonstrated to control biosynthesis of protein, nucleotides and lipids. ${ }^{174}$ For example, glucose-6-phosphate isomerase (GPI) deficiency is the second most frequent cause of inherited glycolytic erythroenzymopathy in humans. ${ }^{175} \mathrm{GPI}$ catalyzes the second step of glycolysis, reversible interconversion of G-6P and fructose-6-phosphate. It is reported that GPI deficiency results in an accumulation of G-6P and mTOR activation. Activated mTORC1 directly phosphorylates lipin-1 and inhibits its localization at ER as well as to nucleus. ${ }^{176}$ Lipin-1 positively regulates triacylglycerol production at ER. ${ }^{176}$ Glycerolipid deficiency is suggested to be associated with non-spherocytic hemolytic anemia in GPI-deficient patients. ${ }^{177}$ In addition, nuclear lipin-1 interacts with transcription factors to regulate genes, thereby regulating fatty acid oxidation and lipogenesis. ${ }^{176}$ These complex transcriptional events mediated by mTORC1/lipin-1 would also relate to the pathologies in GPI-deficient patients. Taken together it will be of considerable importance to determine the physiological and pathophysiological roles of HK-II-mediated control of mTORC1 in various in vivo settings.

\section{Overall Summary of Interaction Between HK-II and Akt/ TORC1 Pathway}

It is intriguing that HK-II, the predominant isoform in insulinsensitive tissues and often upregulated tumors, closely interplays with Akt/mTOR pathway. Akt mediated increases in HK-II expression and mitochondrial association support the growth response through efficient energy production ${ }^{4,17,18}$ as well as preserving mitochondrial integrity. $3,15,28,76,77,79,80,93,96,97,118,178$ In contrast, regulation of the pentose phosphate pathway or glycogenesis by HKs is considered as a cytosolic event. Thus 
Akt-mediated phosphorylation endows HK-II with diverse and complex roles to regulate energy production versus storage, and cell growth and survival by changing its intracellular localization. This is in sharp contrast to HK-I, which is unregulated by Akt. $^{20,49,179,180}$ HK-I more tightly binds to mitochondria with less sensitivity to G-6P-dependent dissociation than HK-II, rendering it primarily a glycolytic enzyme ${ }^{4,5}$ which provides logical support for its predominant expression in the brain, a tissue highly dependent on glucose for energy generation. MitoHK-I displays similar anti-apoptotic characteristics to mitoHK-II thus HK-I appears to be a more specialized isoform geared primarily to facilitate glycolysis and mitochondrial protection. During ischemia, limited energy supplies and delivery of growth factors to cells could reverse the regulation, from Akt-/mTORC1-mediated regulation of HK-II to HK-IImediated inhibition of the mTORC1 pathway stimulating autophagy to prevent metabolic collapse. ${ }^{117}$ From the perspective of mammalian HK evolution, it is interesting that HK-II, but not other isoforms, contains the Akt consensus sequence and TOS motif and also retains two active kinase domains since it is postulated that HK-II mostly closely resembles the ancestral $100 \mathrm{kDa} \mathrm{HK}^{7}$ Thus through evolutionary changes and resultant generation of four isoforms, HKs acquire isoform-specific diversity in their properties; two intact kinase domains (HK-II), Akt-mediated phosphorylation (HK-II), TOS motif to regulate mTORC1 (HK-II), mitochondrial binding (HK-I and HK-II) and two domains versus one domain (HK-I, II, III versus IV) to fulfill distinct, physiologically important functions in different tissues.

\section{Conclusion}

Accumulating evidence reveals that metabolic and cell survival pathways are closely connected and functionally interdependent. Direct molecular signals from metabolic to cell survival pathways allow prompt detection of metabolic status to rapidly activate adaptive responses to ensure preservation of cellular homeostasis. HK-II, the first molecule in glycolysis, serves as a critical nexus of integration among energy production, preservation of mitochondrial integrity and cell viability, as well as energy conservation (Figure 5). These

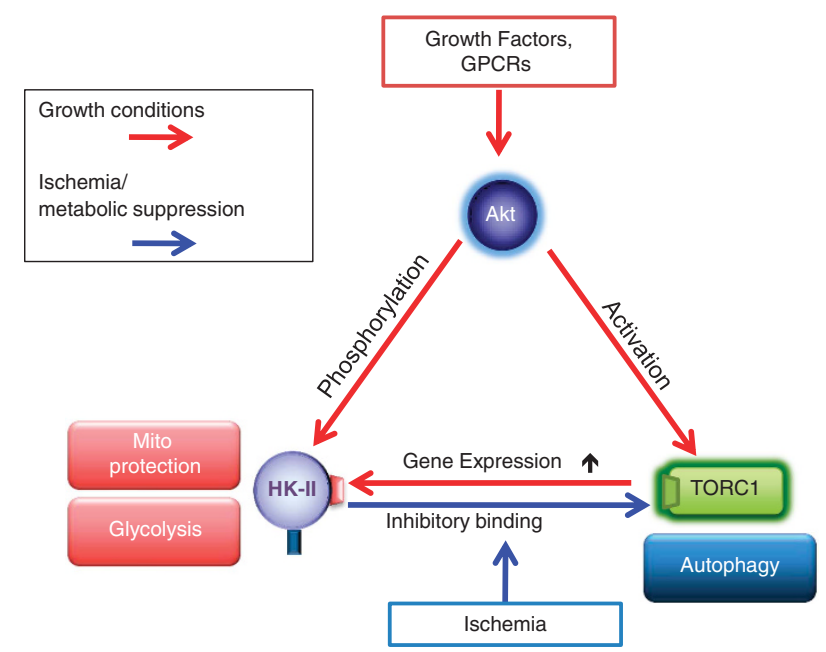

Figure 5 Interaction between HK-II and Akt/mTORC1 pathway diverse effects of HK-II are achieved by changes in its expression levels, intracellular distribution and molecular binding through an interplay with the Akt-/mTORC1-signaling pathways. These findings set the stage for further exploration of the potential importance of HK-II in physiological, as well pathophysiological settings such as cancer, diabetes, inflammation and heart disease, which would lead to new insights for therapeutic interventions.

\section{Conflict of Interest}

The authors declare no conflict of interest.

Acknowledgements. This work was supported by National Institutes of Health grant HL097037 to SM. We thank Dr John E Wilson for insightful and stimulating discussion.

1. Ardehali H, Printz RL, Whitesell RR, May JM, Granner DK. Functional interaction between the $\mathrm{N}$ - and C-terminal halves of human hexokinase II. J Biol Chem 1999; 274: 15986-15989.

2. Pedersen PL. Warburg, me and hexokinase 2: multiple discoveries of key molecular events underlying one of cancers' most common phenotypes, the "Warburg Effect", i.e., elevated glycolysis in the presence of oxygen. J Bioenerg Biomembr 2007; 39: 211-222.

3. Robey RB, Hay N. Mitochondrial hexokinases, novel mediators of the antiapoptotic effects of growth factors and Akt. Oncogene 2006; 25: 4683-4696.

4. Wilson JE. Hexokinases. Rev Physiol Biochem Pharmacol 1995; 126: 65-198.

5. Wilson JE. Isozymes of mammalian hexokinase: structure, subcellular localization and metabolic function. J Exp Biol 2003; 206: 2049-2057.

6. Katzen HM, Schimke RT. Multiple forms of hexokinase in the rat: tissue distribution, age dependency, and properties. Proc Natl Acad Sci USA 1965; 54: 1218-1225.

7. Tsai $\mathrm{HJ}$, Wilson JE. Functional organization of mammalian hexokinases: both $\mathrm{N}$ - and C-terminal halves of the rat type II isozyme possess catalytic sites. Arch Biochem Biophys 1996; 329: 17-23.

8. Heikkinen S, Suppola S, Malkki M, Deeb SS, Janne J, Laakso M. Mouse hexokinase II gene: structure, cDNA, promoter analysis, and expression pattern. Mamm Genome 2000; 11: $91-96$.

9. Mayer SE, Mayfield AC, Haas JA. Heart muscle hexokinase: subcellular distribution and inhibition by glucose 6-phosphate. Mol Pharmacol 1966; 2: 393-405.

10. Rose IA, Warms JV. Mitochondrial hexokinase. Release, rebinding, and location. J Biol Chem 1967; 242: 1635-1645.

11. Sui D, Wilson JE. Structural determinants for the intracellular localization of the isozymes of mammalian hexokinase: intracellular localization of fusion constructs incorporating structural elements from the hexokinase isozymes and the green fluorescent protein. Arch Biochem Biophys 1997; 345: 111-125.

12. Xie GC, Wilson JE. Rat brain hexokinase: the hydrophobic N-terminus of the mitochondrially bound enzyme is inserted in the lipid bilayer. Arch Biochem Biophys 1988; 267: 803-810.

13. Fiek C, Benz R, Roos N, Brdiczka D. Evidence for identity between the hexokinase-binding protein and the mitochondrial porin in the outer membrane of rat liver mitochondria. Biochim Biophys Acta 1982; 688: 429-440.

14. Linden M, Gellerfors $P$, Nelson BD. Pore protein and the hexokinase-binding protein from the outer membrane of rat liver mitochondria are identical. FEBS Lett 1982; 141: 189-192.

15. Pastorino JG, Hoek JB. Hexokinase II: the integration of energy metabolism and control of apoptosis. Curr Med Chem 2003; 10: 1535-1551.

16. Vyssokikh MY, Brdiczka D. The function of complexes between the outer mitochondrial membrane pore (VDAC) and the adenine nucleotide translocase in regulation of energy metabolism and apoptosis. Acta Biochim Pol 2003; 50: 389-404.

17. Arora KK, Pedersen PL. Functional significance of mitochondrial bound hexokinase in tumor cell metabolism. Evidence for preferential phosphorylation of glucose by intramitochondrially generated ATP. J Biol Chem 1988; 263: 17422-17428.

18. Nelson BD, Kabir $F$. The role of the mitochondrial outer membrane in energy metabolism of tumor cells. Biochimie 1986; 68: 407-415.

19. Aubert-Foucher E, Font B, Gautheron DC. Rabbit heart mitochondrial hexokinase: solubilization and general properties. Arch Biochem Biophys 1984; 232: 391-399.

20. John S, Weiss JN, Ribalet B. Subcellular localization of hexokinases I and II directs the metabolic fate of glucose. PLoS One 2011; 6: e17674.

21. Mathupala SP, Ko YH, Pedersen PL. Hexokinase Il: cancer's double-edged sword acting as both facilitator and gatekeeper of malignancy when bound to mitochondria. Oncogene 2006; 25: 4777-4786

22. Kabir F, Wilson JE. Mitochondrial hexokinase in brain of various species: differences in sensitivity to solubilization by glucose 6-phosphate. Arch Biochem Biophys 1993; 300 641-650. 
23. Warburg O, Dickens F, Kaiser BWilhelm-Institut fur Biologie BThe Metabolism of Tumours: Investigations from the Kaiser-Wilhelm Institute for Biology. Berlin-DahlemConstable: London, 1930.

24. Bustamante E, Morris HP, Pedersen PL. Energy metabolism of tumor cells. Requirement for a form of hexokinase with a propensity for mitochondrial binding. J Biol Chem 1981; 256 8699-8704.

25. Rempel A, Mathupala SP, Griffin CA, Hawkins AL, Pedersen PL. Glucose catabolism in cancer cells: amplification of the gene encoding type II hexokinase. Cancer Res 1996; 56 2468-2471.

26. Mathupala SP, Rempel A, Pedersen PL. Aberrant glycolytic metabolism of cancer cells: a remarkable coordination of genetic, transcriptional, post-translational, and mutational events that lead to a critical role for type II hexokinase. J Bioenerg Biomembr 1997; 29: 339-343.

27. Mayer D, Klimek F, Rempel A, Bannasch P. Hexokinase expression in liver preneoplasia and neoplasia. Biochem Soc Trans 1997; 25: 122-127.

28. Pedersen PL, Mathupala S, Rempel A, Geschwind JF, Ko YH. Mitochondrial bound type II hexokinase: a key player in the growth and survival of many cancers and an ideal prospect for therapeutic intervention. Biochim Biophys Acta 2002; 1555: 14-20.

29. Kwee SA, Hernandez B, Chan O, Wong L. Choline kinase alpha and hexokinase-2 protein expression in hepatocellular carcinoma: association with survival. PLoS One 2012; 7: e46591.

30. Wolf A, Agnihotri S, Micallef J, Mukherjee J, Sabha N, Cairns R et al. Hexokinase 2 is a key mediator of aerobic glycolysis and promotes tumor growth in human glioblastoma multiforme. J Exp Med 2011; 208: 313-326.

31. Palmieri D, Fitzgerald D, Shreeve SM, Hua E, Bronder JL, Weil RJ et al. Analyses of resected human brain metastases of breast cancer reveal the association between up-regulation of hexokinase 2 and poor prognosis. Mol Cancer Res 2009; 7: 1438-1445.

32. Miyamoto S, Murphy AN, Brown JH. Akt mediated mitochondrial protection in the heart: metabolic and survival pathways to the rescue. J Bioenerg Biomembr 2009; 41: 169-180.

33. Miyamoto S, Rubio M, Sussman MA. Nuclear and mitochondrial signalling Akts in cardiomyocytes. Cardiovasc Res 2009; 82: 272-285.

34. Scheid MP, Woodgett JR. PKB/AKT: functional insights from genetic models. Nat Rev $\mathrm{Mol}$ Cell Biol 2001; 2: 760-768.

35. Sussman MA, Volkers M, Fischer K, Bailey B, Cottage CT, Din S et al. Myocardial AKT: the omnipresent nexus. Physiol Rev 2011; 91: 1023-1070.

36. Thompson JE, Thompson CB. Putting the rap on Akt. J Clin Oncol 2004; 22: 4217-4226.

37. Hara K, Maruki Y, Long X, Yoshino K-i, Oshiro N, Hidayat S et al. Raptor, a binding partner of target of rapamycin (TOR), mediates TOR action. Cell 2002; 110: 177-189.

38. Kim DH, Sarbassov DD, Ali SM, King JE, Latek RR, Erdjument-Bromage $\mathrm{H}$ et al. mTOR interacts with raptor to form a nutrient-sensitive complex that signals to the cell growth machinery. Cell 2002; 110: 163-175.

39. Sarbassov DD, Ali SM, Kim D-H, Guertin DA, Latek RR, Erdjument-Bromage H et al. Rictor, a novel binding partner of mTOR, defines a rapamycin-insensitive and raptor-independent pathway that regulates the cytoskeleton. Curr Biol 2004; 14: 1296-1302.

40. Wullschleger S, Loewith R, Hall MN. TOR signaling in growth and metabolism. Cell 2006; 124: 471-484

41. Katzen HM. The effect of diabetes and insulin in vivo and in vitro on a low $\mathrm{Km}$ form of hexokinase from various rat tissues. Biochem Biophys Res Commun 1966; 24: 531-536.

42. Katzen HM, Soderman DD, Wiley CE. Multiple forms of hexokinase. Activities associated with subcellular particulate and soluble fractions of normal and streptozotocin diabetic rat tissues. J Biol Chem 1970; 245: 4081-4096.

43. Burcelin R, Printz RL, Kande J, Assan R, Granner DK, Girard J. Regulation of glucose transporter and hexokinase II expression in tissues of diabetic rats. Am J Physiol 1993; 265 E392-E401.

44. Printz RL, Koch S, Potter LR, O'Doherty RM, Tiesinga JJ, Moritz S et al. Hexokinase II mRNA and gene structure, regulation by insulin, and evolution. J Biol Chem 1993; 268 5209-5219.

45. Gurel E, Ustunova S, Kapucu A, Yilmazer N, Eerbeek O, Nederlof R et al. Hexokinase cellular trafficking in ischemia-reperfusion and ischemic preconditioning is altered in type diabetic heart. Mol Biol Rep 2013; 40: 4153-4160.

46. Chehtane M, Khaled AR. Interleukin-7 mediates glucose utilization in lymphocytes through transcriptional regulation of the hexokinase II gene. Am J Physiol Cell Physiol 2010; 298: C1560-C1571

47. Culbert AA, Tavare JM. Multiple signalling pathways mediate insulin-stimulated gene expression in 3T3-L1 adipocytes. Biochim Biophys Acta 2002; 1578: 43-50.

48. Lee AW, States DJ. Colony-stimulating factor-1 requires PI3-kinase-mediated metabolism for proliferation and survival in myeloid cells. Cell Death Differ 2006; 13: 1900-1914.

49. Osawa H, Sutherland C, Robey RB, Printz RL, Granner DK. Analysis of the signaling pathway involved in the regulation of hexokinase II gene transcription by insulin. J Biol Chem 1996; 271: 16690-16694.

50. Duarte Al, Santos P, Oliveira CR, Santos MS, Rego AC. Insulin neuroprotection against oxidative stress is mediated by Akt and GSK-3beta signaling pathways and changes in protein expression. Biochim Biophys Acta 2008; 1783: 994-1002.

51. Vogt $\mathrm{C}$, Ardehali $\mathrm{H}$, lozzo P, Yki-Jarvinen $\mathrm{H}$, Koval J, Maezono $\mathrm{K}$ et al. Regulation of hexokinase II expression in human skeletal muscle in vivo. Metabolism 2000; 49:814-818.

52. Bhaskar PT, Nogueira V, Patra KC, Jeon SM, Park Y, Robey RB et al. mTORC1 hyperactivity inhibits serum deprivation-induced apoptosis via increased hexokinase II and GLUT1 expression, sustained Mcl-1 expression, and glycogen synthase kinase 3beta inhibition. Mol Cell Biol 2009; 29: 5136-5147.
53. Duvel K, Yecies JL, Menon S, Raman P, Lipovsky Al, Souza AL et al. Activation of a metabolic gene regulatory network downstream of mTOR complex 1. Mol Cell 2010; 39: 171-183.

54. Riddle SR, Ahmad A, Ahmad S, Deeb SS, Malkki M, Schneider BK et al. Hypoxia induces hexokinase II gene expression in human lung cell line A549. Am J Physiol Lung Cell Mol Physiol 2000; 278: L407-L416.

55. Mathupala SP, Rempel A, Pedersen PL. Glucose catabolism in cancer cells: identification and characterization of a marked activation response of the type II hexokinase gene to hypoxic conditions. J Biol Chem 2001; 276: 43407-43412.

56. Gwak GY, Yoon JH, Kim KM, Lee HS, Chung JW, Gores GJ. Hypoxia stimulates proliferation of human hepatoma cells through the induction of hexokinase II expression. $J$ Hepatol 2005; 42: 358-364.

57. Kim JW, Gao P, Liu YC, Semenza GL, Dang CV. Hypoxia-inducible factor 1 and dysregulated c-Myc cooperatively induce vascular endothelial growth factor and metabolic switches hexokinase 2 and pyruvate dehydrogenase kinase 1. Mol Cell Biol 2007; 27: 7381-7393.

58. DeBerardinis RJ, Lum JJ, Hatzivassiliou G, Thompson CB. The biology of cancer: metabolic reprogramming fuels cell growth and proliferation. Cell Metab 2008; 7: 11-20.

59. Yuan HX, Xiong Y, Guan KL. Nutrient sensing, metabolism, and cell growth control. Mol Cell 2013; 49: 379-387.

60. Sato-Tadano A, Suzuki T, Amari M, Takagi K, Miki Y, Tamaki K et al. Hexokinase II in breast carcinoma: a potent prognostic factor associated with hypoxia-inducible factor-1alpha and Ki-67. Cancer Sci 2013; 104: 1380-1388.

61. Denko NC. Hypoxia, HIF1 and glucose metabolism in the solid tumour. Nat Rev Cancer 2008; 8: 705-713

62. Zhong H, Chiles K, Feldser D, Laughner E, Hanrahan C, Georgescu MM et al. Modulation of hypoxia-inducible factor 1alpha expression by the epidermal growth factor/ phosphatidylinositol 3-kinase/PTEN/AKT/FRAP pathway in human prostate cancer cells: implications for tumor angiogenesis and therapeutics. Cancer Res 2000; 60: 1541-1545.

63. Laughner E, Taghavi P, Chiles K, Mahon PC, Semenza GL. HER2 (neu) signaling increases the rate of hypoxia-inducible factor 1alpha (HIF-1alpha) synthesis: novel mechanism for HIF-1-mediated vascular endothelial growth factor expression. Mol Cell Biol 2001; $21: 3995-4004$

64. Jiang BH, Jiang G, Zheng JZ, Lu Z, Hunter T, Vogt PK. Phosphatidylinositol 3-kinase signaling controls levels of hypoxia-inducible factor 1. Cell Growth Differ 2001; 12: 363-369.

65. Majumder PK, Febbo PG, Bikoff R, Berger R, Xue Q, McMahon LM et al. mTOR inhibition reverses Akt-dependent prostate intraepithelial neoplasia through regulation of apoptotic and HIF-1-dependent pathways. Nat Med 2004; 10: 594-601.

66. Tong AW, Nemunaitis J. Modulation of miRNA activity in human cancer: a new paradigm for cancer gene therapy? Cancer Gene Ther 2008; 15: 341-355.

67. Fang R, Xiao T, Fang Z, Sun Y, Li F, Gao Y et al. MicroRNA-143 (miR-143) regulates cancer glycolysis via targeting hexokinase 2 gene. J Biol Chem 2012; 287: 23227-23235.

68. Gregersen LH, Jacobsen A, Frankel LB, Wen J, Krogh A, Lund AH. MicroRNA-143 downregulates hexokinase 2 in colon cancer cells. BMC Cancer 2012; 12: 232.

69. Peschiaroli A, Giacobbe A, Formosa A, Markert EK, Bongiorno-Borbone L, Levine AJ et al. miR-143 regulates hexokinase 2 expression in cancer cells. Oncogene 2013; 32: 797-802.

70. Yoshino H, Enokida H, Itesako T, Kojima S, Kinoshita T, Tatarano S et al. Tumorsuppressive microRNA-143/145 cluster targets hexokinase-2 in renal cell carcinoma. Cancer Sci 2013; 104: 1567-1574.

71. Zhao S, Liu H, Liu Y, Wu J, Wang C, Hou X et al. miR-143 inhibits glycolysis and depletes stemness of glioblastoma stem-like cells. Cancer Lett 2013; 333: 253-260.

72. Li C, Liu Y, Liu J, Chen Y, Li Z, Chen X et al. Rapamycin inhibits human glioma cell proliferation through down-regulating mammalian target of rapamycin pathway and upregulating microRNA-143. Head Neck Oncol 2012; 4: 66

73. Matkovich SJ, Hu Y, Dorn GW 2nd. Regulation of cardiac microRNAs by cardiac microRNAs. Circ Res 2013; 113: 62-71.

74. Jiang S, Zhang HW, Lu MH, He XH, Li Y, Gu H et al. MicroRNA-155 functions as an OncomiR in breast cancer by targeting the suppressor of cytokine signaling 1 gene. Cancer Res 2012; 70: 3119-3127.

75. Ahmad A, Ahmad S, Schneider BK, Allen CB, Chang LY, White CW. Elevated expression of hexokinase II protects human lung epithelial-like A549 cells against oxidative injury. Am J Physiol Lung Cell Mol Physiol 2002; 283: L573-L584.

76. Bryson JM, Coy PE, Gottlob K, Hay N, Robey RB. Increased hexokinase activity, of either ectopic or endogenous origin, protects renal epithelial cells against acute oxidant-induced cell death. J Biol Chem 2002; 277: 11392-11400.

77. da-Silva WS, Gomez-Puyou A, de Gomez-Puyou MT, Moreno-Sanchez R, De Felice FG, de Meis $L$ et al. Mitochondrial bound hexokinase activity as a preventive antioxidant defense: steady-state ADP formation as a regulatory mechanism of membrane potential and reactive oxygen species generation in mitochondria. J Biol Chem 2004; 279: 39846-39855.

78. Pastorino JG, Shulga N, Hoek JB. Mitochondrial binding of hexokinase II inhibits Bax-induced cytochrome c release and apoptosis. J Biol Chem 2002; 277: 7610-7618.

79. Roberts DJ, Tan-Sah VP, Smith JM, Miyamoto S. Akt phosphorylates HK-II at Thr-473 and increases mitochondrial HK-II association to protect cardiomyocytes. J Biol Chem 2013; 288: 23798-23806

80. Sun L, Shukair S, Naik TJ, Moazed F, Ardehali H. Glucose phosphorylation and mitochondrial binding are required for the protective effects of hexokinases I and II. Mol Cell Biol 2008; 28: 1007-1017. 
81. Corona JC, Gimenez-Cassina A, Lim F, Diaz-Nido J. Hexokinase II gene transfer protects against neurodegeneration in the rotenone and MPTP mouse models of Parkinson's disease. J Neurosci Res 2010; 88: 1943-1950.

82. McCommis KS, Douglas DL, Krenz M, Baines CP. Cardiac-specific hexokinase 2 overexpression attenuates hypertrophy by increasing pentose phosphate pathway flux. J Am Heart Assoc 2013; 2: e000355.

83. Wu R, Smeele KM, Wyatt E, Ichikawa Y, Eerbeek O, Sun L et al. Reduction in hexokinase II levels results in decreased cardiac function and altered remodeling after ischemia/ reperfusion injury. Circ Res 2011; 108: 60-69.

84. Wu R, Wyatt E, Chawla K, Tran M, Ghanefar M, Laakso M et al. Hexokinase II knockdown results in exaggerated cardiac hypertrophy via increased ROS production. EMBO Mol Med 2012; 4: 633-646.

85. Rathmell JC, Fox CJ, Plas DR, Hammerman PS, Cinalli RM, Thompson CB. Akt-directed glucose metabolism can prevent Bax conformation change and promote growth factor-independent survival. Mol Cell Biol 2003; 23: 7315-7328.

86. Tait SW, Green DR. Mitochondrial regulation of cell death. Cold Spring Harb Perspect Biol 2013; 5: pii: a008706.

87. Rasola A, Sciacovelli M, Pantic B, Bernardi P. Signal transduction to the permeability transition pore. FEBS Lett 2010; 584: 1989-1996.

88. Fulda S, Galluzzi L, Kroemer G. Targeting mitochondria for cancer therapy. Nat Rev Drug Discov 2010; 9: 447-464

89. Baines CP. The cardiac mitochondrion: nexus of stress. Annu Rev Physiol 2010; 72: 61-80.

90. Murphy $E$, Steenbergen $C$. Mechanisms underlying acute protection from cardiac ischemia-reperfusion injury. Physiol Rev 2008; 88: 581-609.

91. Reed JC. Bcl-2-family proteins and hematologic malignancies: history and future prospects Blood 2008; 111: 3322-3330.

92. Gall JM, Wong V, Pimental DR, Havasi A, Wang Z, Pastorino JG et al. Hexokinase regulates Bax-mediated mitochondrial membrane injury following ischemic stress. Kidney Int 2011; 79: 1207-1216.

93. Majewski N, Nogueira V, Bhaskar P, Coy PE, Skeen JE, Gottlob K et al. Hexokinasemitochondria interaction mediated by Akt is required to inhibit apoptosis in the presence or absence of Bax and Bak. Mol Cell 2004; 16: 819-830.

94. Majewski N, Nogueira V, Robey RB, Hay N. Akt inhibits apoptosis downstream of BID cleavage via a glucose-dependent mechanism involving mitochondrial hexokinases. $\mathrm{Mol}$ Cell Biol 2004; 24: 730-740.

95. Vyssokikh MY, Zorova L, Zorov D, Heimlich G, Jurgensmeier JJ, Brdiczka D. Bax releases cytochrome $c$ preferentially from a complex between porin and adenine nucleotide translocator. Hexokinase activity suppresses this effect. Mol Biol Rep 2002; 29: 93-96.

96. Chiara F, Castellaro D, Marin O, Petronilli V, Brusilow WS, Juhaszova M et al. Hexokinase II detachment from mitochondria triggers apoptosis through the permeability transition pore independent of voltage-dependent anion channels. PLoS One 2008; 3: e1852.

97. Miyamoto S, Murphy AN, Brown JH. Akt mediates mitochondrial protection in cardiomyocytes through phosphorylation of mitochondrial hexokinase-II. Cell Death Differ 2008; 15: 521-529.

98. Smeele KM, Southworth R, Wu R, Xie C, Nederlof R, Warley A et al. Disruption of hexokinase II-mitochondrial binding blocks ischemic preconditioning and causes rapid cardiac necrosis. Circ Res 2011; 108: 1165-1169.

99. Mailloux RJ, Dumouchel T, Aguer C, deKemp R, Beanlands R, Harper ME. Hexokinase II acts through UCP3 to suppress mitochondrial reactive oxygen species production and maintain aerobic respiration. Biochem J 2011; 437: 301-311.

100. Baines CP, Kaiser RA, Purcell NH, Blair NS, Osinska H, Hambleton MA et al. Loss of cyclophilin $\mathrm{D}$ reveals a critical role for mitochondrial permeability transition in cell death. Nature 2005; 434: 658-662.

101. Nakagawa T, Shimizu S, Watanabe T, Yamaguchi O, Otsu K, Yamagata $\mathrm{H}$ et al. Cyclophilin D-dependent mitochondrial permeability transition regulates some necrotic but not apoptotic cell death. Nature 2005; 434: 652-658.

102. Machida K, Ohta Y, Osada H. Suppression of apoptosis by cyclophilin D via stabilization of hexokinase II mitochondrial binding in cancer cells. J Biol Chem 2006; 281: 14314-14320.

103. Shulga N, Wilson-Smith R, Pastorino JG. Sirtuin-3 deacetylation of cyclophilin D induces dissociation of hexokinase II from the mitochondria. J Cell Sci 2010; 123: 894-902.

104. Verma M, Shulga N, Pastorino JG. Sirtuin-3 modulates Bak- and Bax-dependent apoptosis. J Cell Sci 2013; 126: 274-288.

105. Wei L, Zhou Y, Dai Q, Qiao C, Zhao L, Hui $\mathrm{H}$ et al. Oroxylin A induces dissociation of hexokinase II from the mitochondria and inhibits glycolysis by SIRT3-mediated deacetylation of cyclophilin D in breast carcinoma. Cell Death Dis 2013; 4: e601.

106. Woodfield K, Ruck A, Brdiczka D, Halestrap AP. Direct demonstration of a specific interaction between cyclophilin- $D$ and the adenine nucleotide translocase confirms their role in the mitochondrial permeability transition. Biochem J 1998; 336(Pt 2): 287-290.

107. Crompton M. The mitochondrial permeability transition pore and its role in cell death. Biochem J 1999; 341(Pt 2): 233-249.

108. Akao M, O'Rourke B, Kusuoka H, Teshima Y, Jones SP, Marban E. Differential actions of cardioprotective agents on the mitochondrial death pathway. Circ Res 2003; 92: 195-202.

109. Baines CP, Kaiser RA, Sheiko T, Craigen WJ, Molkentin JD. Voltage-dependent anion channels are dispensable for mitochondrial-dependent cell death. Nat Cell Biol 2007; 9: 550-555.

110. Kokoszka JE, Waymire KG, Levy SE, Sligh JE, Cai J, Jones DP et al. The ADP/ATP translocator is not essential for the mitochondrial permeability transition pore. Nature 2004; 427: 461-465.
111. Krauskopf A, Eriksson O, Craigen WJ, Forte MA, Bernardi P. Properties of the permeability transition in VDAC1 ( - / - ) mitochondria. Biochim Biophys Acta 2006; 1757: 590-595.

112. Giorgio V, von Stockum S, Antoniel M, Fabbro A, Fogolari F, Forte M et al. Dimers of mitochondrial ATP synthase form the permeability transition pore. Proc Natl Acad Sci USA 2013; 110: 5887-5892.

113. Whelan RS, Konstantinidis K, Wei AC, Chen Y, Reyna DE, Jha S et al. Bax regulates primary necrosis through mitochondrial dynamics. Proc Natl Acad Sci USA 2012; 109: $6566-6571$.

114. Karch J, Kwong JQ, Burr AR, Sargent MA, Elrod JW, Peixoto PM et al. Bax and Bak function as the outer membrane component of the mitochondrial permeability pore in regulating necrotic cell death in mice. Elife 2013; 2: e00772.

115. Patra KC, Wang Q, Bhaskar PT, Miller L, Wang Z, Wheaton W et al. Hexokinase 2 is required for tumor initiation and maintenance and its systemic deletion is therapeutic in mouse models of cancer. Cancer Cell 2013; 24: 213-228.

116. Favaro E, Bensaad K, Chong MG, Tennant DA, Ferguson DJ, Snell C et al. Glucose utilization via glycogen phosphorylase sustains proliferation and prevents premature senescence in cancer cells. Cell Metab 2012; 16: 751-764.

117. Roberts DJ, Tan-Sah VP, Ding EY, Smith JM, Miyamoto S. Hexokinase-II positively regulates glucose starvation induced autophagy through TORC1 inhibition. Mol Cell 2014 53: $521-533$.

118. Gottlob K, Majewski N, Kennedy S, Kandel E, Robey RB, Hay N. Inhibition of early apoptotic events by Akt/PKB is dependent on the first committed step of glycolysis and mitochondria hexokinase. Genes Dev 2001; 15: 1406-1418.

119. Russell RR 3rd, Mrus JM, Mommessin Jl, Taegtmeyer H. Compartmentation of hexokinase in rat heart. A critical factor for tracer kinetic analysis of myocardial glucose metabolism. J Clin Invest 1992; 90: 1972-1977.

120. Zuurbier CJ, Eerbeek O, Meijer AJ. Ischemic preconditioning, insulin, and morphine all cause hexokinase redistribution. Am J Physiol Heart Circ Physiol 2005; 289: H496-H499.

121. Southworth R, Davey KA, Warley A, Garlick PB. A reevaluation of the roles of hexokinase I and II in the heart. Am J Physiol Heart Circ Physiol 2007; 292: H378-H386.

122. Ahn KJ, Hwang HS, Park JH, Bang SH, Kang WJ, Yun M et al. Evaluation of the role of hexokinase type II in cellular proliferation and apoptosis using human hepatocellular carcinoma cell lines. J Nucl Med 2009; 50: 1525-1532.

123. Betz C, Stracka D, Prescianotto-Baschong C, Frieden M, Demaurex N, Hall MN. Feature Article: mTOR complex 2-Akt signaling at mitochondria-associated endoplasmic reticulum membranes (MAM) regulates mitochondrial physiology. Proc Natl Acad Sci USA 2013; 110: 12526-12534

124. Miyamoto S, Purcell NH, Smith JM, Gao T, Whittaker R, Huang K et al. PHLPP-1 negatively regulates Akt activity and survival in the heart. Circ Res 2010; 107: 476-484.

125. Picone P, Giacomazza D, Vetri V, Carrotta R, Militello V, San Biagio PL et al. Insulin-activated Akt rescues $A \beta$ oxidative stress-induced cell death by orchestrating molecular trafficking. Aging Cell 2011; 10: 832-843.

126. Rajala A, Gupta VK, Anderson RE, Rajala RV. Light activation of the insulin receptor regulates mitochondrial hexokinase. A possible mechanism of retinal neuroprotection Mitochondrion 2013; 13: 566-576.

127. Brognard J, Sierecki E, Gao T, Newton AC. PHLPP and a second isoform, PHLPP2, differentially attenuate the amplitude of Akt signaling by regulating distinct Akt isoforms. $\mathrm{Mol}$ Cell 2007; 25: 917-931.

128. Gao T, Furnari F, Newton AC. PHLPP: a phosphatase that directly dephosphorylates Akt, promotes apoptosis, and suppresses tumor growth. Mol Cell 2005; 18: 13-24.

129. Hirano I, Nakamura S, Yokota D, Ono T, Shigeno K, Fujisawa S et al. Depletion of Pleckstrin homology domain leucine-rich repeat protein phosphatases 1 and 2 by Bcr-Abl promotes chronic myelogenous leukemia cell proliferation through continuous phosphorylation of Akt isoforms. J Biol Chem 2009; 284: 22155-22165.

130. Liu J, Weiss HL, Rychahou P, Jackson LN, Evers BM, Gao T. Loss of PHLPP expression in colon cancer: role in proliferation and tumorigenesis. Oncogene 2009; 28: 994-1004.

131. Xie G, Wilson JE. Tetrameric structure of mitochondrially bound rat brain hexokinase: a crosslinking study. Arch Biochem Biophys 1990; 276: 285-293.

132. Grimm S, Brdiczka D. The permeability transition pore in cell death. Apoptosis 2007; 12 841-855.

133. Pastorino JG, Hoek JB, Shulga N. Activation of glycogen synthase kinase 3beta disrupts the binding of hexokinase II to mitochondria by phosphorylating voltage-dependent anion channel and potentiates chemotherapy-induced cytotoxicity. Cancer Res 2005; 65 10545-10554.

134. Miura T, Tanno M. The mPTP and its regulatory proteins: final common targets of signalling pathways for protection against necrosis. Cardiovasc Res 2012; 94: 181-189.

135. Pantic B, Trevisan E, Citta A, Rigobello MP, Marin O, Bernardi P et al. Myotonic dystrophy protein kinase (DMPK) prevents ROS-induced cell death by assembling a hexokinase II-Src complex on the mitochondrial surface. Cell Death Dis 2013; 4: e858.

136. Mailloux RJ, Harper ME. Uncoupling proteins and the control of mitochondrial reactive oxygen species production. Free Radic Biol Med 2011; 51: 1106-1115.

137. Vousden KH, Ryan KM. p53 and metabolism. Nat Rev Cancer 2009; 9: 691-700

138. Green DR, Chipuk JE. p53 and metabolism: inside the TIGAR. Cell 2006; 126: 30-32.

139. Bensaad K, Tsuruta A, Selak MA, Vidal MN, Nakano K, Bartrons R et al. TIGAR, a p53-inducible regulator of glycolysis and apoptosis. Cell 2006; 126: 107-120.

140. Li H, Jogl G. Structural and biochemical studies of TIGAR (TP53-induced glycolysis and apoptosis regulator). J Biol Chem 2009; 284: 1748-1754. 
141. Kawauchi K, Araki K, Tobiume K, Tanaka N. Loss of p53 enhances catalytic activity of IKKbeta through O-linked beta-N-acetyl glucosamine modification. Proc Natl Acad Sci USA 2009; 106: 3431-3436.

142. Kawauchi K, Araki K, Tobiume K, Tanaka N. p53 regulates glucose metabolism through an IKK-NF-kappaB pathway and inhibits cell transformation. Nat Cell Biol 2008; 10 611-618.

143. Puzio-Kuter AM. The role of p53 in metabolic regulation. Genes Cancer 2010; 2: 385-391.

144. Cheung EC, Ludwig RL, Vousden KH. Mitochondrial localization of TIGAR under hypoxia stimulates HK2 and lowers ROS and cell death. Proc Natl Acad Sci USA 2012; 109 20491-20496.

145. Deter RL, De Duve C. Influence of glucagon, an inducer of cellular autophagy, on some physical properties of rat liver lysosomes. J Cell Biol 1967; 33: 437-449.

146. Levine B, Kroemer G. Autophagy in the pathogenesis of disease. Cell 2008; 132: 27-42.

147. Lum JJ, Bauer DE, Kong M, Harris MH, Li C, Lindsten T et al. Growth factor regulation of autophagy and cell survival in the absence of apoptosis. Cell 2005; 120: 237-248.

148. Rabinowitz JD, White E. Autophagy and metabolism. Science 2010; 330: 1344-1348.

149. Whelan RS, Kaplinskiy V, Kitsis RN. Cell death in the pathogenesis of heart disease: mechanisms and significance. Annu Rev Physiol 2010; 72: 19-44.

150. Kim KH, Lee MS. Autophagy-a key player in cellular and body metabolism. Nat Rev Endocrinol 2014; 10: 322-337.

151. Guo JY, Xia B, White E. Autophagy-mediated tumor promotion. Cell 2013; 155: 1216-1219.

152. Green DR, Levine B. To be or not to be? How selective autophagy and cell death govern cell fate. Cell 2014; 157: 65-75.

153. Sciarretta S, Volpe M, Sadoshima J. Mammalian target of rapamycin signaling in cardiac physiology and disease. Circ Res 2014; 114: 549-564.

154. Sengupta S, Peterson TR, Sabatini DM. Regulation of the mTOR complex 1 pathway by nutrients, growth factors, and stress. Mol Cell 2010; 40: 310-322.

155. Kim J, Kundu M, Viollet B, Guan KL. AMPK and mTOR regulate autophagy through direct phosphorylation of Ulk1. Nat Cell Biol 2011; 13: 132-141.

156. Shang L, Chen S, Du F, Li S, Zhao L, Wang X. Nutrient starvation elicits an acute autophagic response mediated by Ulk1 dephosphorylation and its subsequent dissociation from AMPK. Proc Natl Acad Sci USA 2011; 108: 4788-4793.

157. Egan DF, Shackelford DB, Mihaylova MM, Gelino S, Kohnz RA, Mair W et al. Phosphorylation of ULK1 (hATG1) by AMP-activated protein kinase connects energy sensing to mitophagy. Science 2011; 331: 456-461.

158. Ganley IG, Lam du H, Wang J, Ding X, Chen S, Jiang X. ULK1.ATG13.FIP200 complex mediates mTOR signaling and is essential for autophagy. J Biol Chem 2009; 284 12297-12305.

159. Hosokawa N, Hara T, Kaizuka T, Kishi C, Takamura A, Miura Y et al. Nutrient-dependen mTORC1 association with the ULK1-Atg13-FIP200 complex required for autophagy. Mol Biol Cell 2009; 20: 1981-1991.

160. Jung $\mathrm{CH}$, Jun CB, Ro SH, Kim YM, Otto NM, Cao J et al. ULK-Atg13-FIP200 complexes mediate mTOR signaling to the autophagy machinery. Mol Biol Cell 2009; 20: 1992-2003.

161. Cheong H, Lu C, Lindsten T, Thompson CB. Therapeutic targets in cancer cell metabolism and autophagy. Nat Biotechnol 2012; 30: 671-678.

162. Raez LE, Papadopoulos K, Ricart AD, Chiorean EG, Dipaola RS, Stein MN et al. A phase I dose-escalation trial of 2-deoxy-D-glucose alone or combined with docetaxel in patients with advanced solid tumors. Cancer Chemother Pharmacol 2013; 71: 523-530.
163. Zhao Y, Butler EB, Tan M. Targeting cellular metabolism to improve cancer therapeutics. Cell Death Dis 2013; 4: e532.

164. DiPaola RS, Dvorzhinski D, Thalasila A, Garikapaty V, Doram D, May M et al. Therapeutic starvation and autophagy in prostate cancer: a new paradigm for targeting metabolism in cancer therapy. Prostate 2008; 68: 1743-1752.

165. Wang Q, Liang B, Shirwany NA, Zou MH. 2-Deoxy-D-glucose treatment of endothelial cells induces autophagy by reactive oxygen species-mediated activation of the AMP-activated protein kinase. PLoS One 2011; 6: e17234.

166. Xi H, Kurtoglu M, Liu H, Wangpaichitr M, You M, Liu X et al. 2-Deoxy-D-glucose activates autophagy via endoplasmic reticulum stress rather than ATP depletion. Cancer Chemother Pharmacol 2011; 67: 899-910.

167. Nojima H, Tokunaga C, Eguchi S, Oshiro N, Hidayat S, Yoshino K et al. The mammalian target of rapamycin (mTOR) partner, raptor, binds the mTOR substrates p70 S6 kinase and 4E-BP1 through their TOR signaling (TOS) motif. J Biol Chem 2003; 278: 15461-15464.

168. Schalm SS, Blenis J. Identification of a conserved motif required for mTOR signaling. Curr Biol 2002; 12: 632-639.

169. Betz C, Hall MN. Where is mTOR and what is it doing there? J Cell Biol 2013; 203: 563-574.

170. Kim SG, Hoffman GR, Poulogiannis G, Buel GR, Jang YJ, Lee KW et al. Metabolic stress controls mTORC1 lysosomal localization and dimerization by regulating the TTT-RUVBL1/2 complex. Mol Cell 2013; 49: 172-185.

171. Sancak Y, Bar-Peled L, Zoncu R, Markhard AL, Nada S, Sabatini DM. Ragulator-Rag complex targets mTORC1 to the lysosomal surface and is necessary for its activation by amino acids. Cell 2010; 141: 290-303.

172. Sharma S, Guthrie PH, Chan SS, Haq S, Taegtmeyer H. Glucose phosphorylation is required for insulin-dependent mTOR signalling in the heart. Cardiovasc Res 2007; 76 : $71-80$

173. Sen S, Kundu BK, Wu HC, Hashmi SS, Guthrie P, Locke LW et al. Glucose regulation of load-induced mTOR signaling and ER stress in mammalian heart. J Am Heart Assoc 2013; 2: 0004796.

174. Shimobayashi M, Hall MN. Making new contacts: the mTOR network in metabolism and signalling crosstalk. Nat Rev Mol Cell Biol 2014; 15: 155-162.

175. Kugler W, Lakomek M. Glucose-6-phosphate isomerase deficiency. Baillieres Best Pract Res Clin Haematol 2000; 13: 89-101.

176. Csaki LS, Dwyer JR, Fong LG, Tontonoz P, Young SG, Reue K. Lipins, lipinopathies, and the modulation of cellular lipid storage and signaling. Prog Lipid Res 2013; 52: 305-316.

177. Haller JF, Krawczyk SA, Gostilovitch L, Corkey BE, Zoeller RA. Glucose-6-phosphate isomerase deficiency results in mTOR activation, failed translocation of lipin 1alpha to the nucleus and hypersensitivity to glucose: implications for the inherited glycolytic disease. Biochim Biophys Acta 2011; 1812: 1393-1402.

178. Mathupala SP, Ko YH, Pedersen PL. Hexokinase-2 bound to mitochondria: cancer's stygian link to the "Warburg Effect" and a pivotal target for effective therapy. Semin Cancer Biol 2009; 19: 17-24.

179. Pendergrass $\mathrm{M}$, Koval J, Vogt $\mathrm{C}$, Yki-Jarvinen $\mathrm{H}$, lozzo P, Pipek R et al. Insulin-induced hexokinase II expression is reduced in obesity and NIDDM. Diabetes 1998; 47: 387-394.

180. Vogt C, Yki-Jarvinen H, lozzo P, Pipek R, Pendergrass M, Koval J et al. Effects of insulin on subcellular localization of hexokinase II in human skeletal muscle in vivo. $J$ Clin Endocrinol Metab 1998; 83: 230-234. 